\title{
Understanding the experience of psychopathology after intimate partner violence: the role of personality
}

\author{
Paulo A.S. Moreira ${ }^{\text {Corresp.. }}{ }^{1,2}$ ， Márcia Pinto ${ }^{2,3}$, C. Robert Cloninger ${ }^{4}$, Daniela Rodrigues ${ }^{2,5}$, Carlos Fernandes \\ da Silva ${ }^{6,7}$ \\ 1 Instituto de Psicologia e de Ciências da Educação, Universidade Lusíada - Norte(Porto), Porto, Portugal \\ 2 Centro de Investigação em Psicologia para o Desenvolvimento, CIPD, Porto, Portugal \\ 3 Centro de Acolhimento Temporário Âncora, Associação para o Desenvolvimento de Rebordosa, Rebordosa, Portugal \\ 4 School of Medicine, Washington University in St. Louis, St. Louis, MO, United States \\ 5 Estabelecimento Prisional de Santa Cruz do Bispo - Masculino, Direção Geral de Reinserção e Serviços Prisionais, Matosinhos, Portugal \\ 6 Departamento de Educação e Psicologia, Universidade de Aveiro, Aveiro, Portugal \\ 7 Center for Health Technology and Services Research, CINTESIS, Porto, Portugal \\ Corresponding Author: Paulo A.S. Moreira \\ Email address: paulomoreira@por.ulusiada.pt
}

Objective(s): To fully understand the dynamics of Intimate Partner Violence (IPV) it is necessary to understand the role of personality. The current understanding of which personality characteristics are associated with IPV victimization is, however, far from comprehensive. Given this gap in the literature, our objective was to examine the associations between the dimensions of the psychobiological model of personality and psychopathological symptoms in women who had experienced IPV. [p]

Methods: Using a case-control design, a group of women who had experienced IPV and who were living in shelters $(n=50)$ were compared to a group of control women who had not experienced IPV $(n=50)$. All women completed the Temperament and Character Inventory - Revised and the Brief Symptom Inventory. [p]

Results: Victims of IPV showed significantly higher levels of Harm Avoidance and SelfTranscendence, and lower levels of Reward Dependence and Self-Directedness, than the non-IPV control group. Victims of IPV also reported elevated levels of psychopathological symptoms. Personality dimensions showed a broadly consistent pattern of associations across different psychopathological symptoms. A regression analysis indicated that Novelty Seeking was negatively associated with psychopathological symptoms in victims of IPV, but not significantly associated in non-victims. [p]

Conclusions: The study highlights the important role of Harm Avoidance and SelfDirectedness for understanding psychopathological symptoms. Novelty Seeking appears to play an important role in the expression of individuals' experiences of IPV. These results have important implications for research and practice, particularly the development and implementation of interventions. [p] 


\section{Understanding the experience of psychopathology after intimate partner}

2 violence: the role of personality

4 Paulo A.S. Moreira ${ }^{1,2}$, Márcia Pinto ${ }^{2,3}$, C. Robert Cloninger 4 , Daniela Rodrigues ${ }^{2,5}$, Carlos

5 Fernandes da Silva ${ }^{6,7}$

6

7

8

${ }^{1}$ Instituto de Psicologia e de Ciências da Educação, Universidade Lusíada Norte (Porto), Porto, Portugal

${ }^{2}$ Centro de Investigação em Psicologia para o Desenvolvimento, CIPD, Porto, Portugal

${ }^{3}$ Centro de Acolhimento Temporário Âncora, Associação para o Desenvolvimento de Rebordosa, Rebordosa, Portugal.

${ }^{4}$ School of Medicine, Washington University in St Louis, St. Louis, MO, USA

${ }^{5}$ Estabelecimento Prisional de Santa Cruz do Bispo - Masculino, Direção Geral de Reinserção e Serviços Prisionais, Matosinhos.

${ }^{6}$ Universidade de Aveiro, Departamento de Educação e Psicologia, Aveiro, Portugal

${ }^{7}$ Center for Health Technology and Services Research, CINTESIS, Porto, Portugal

Corresponding Author:

Paulo Moreira ${ }^{1,2}$

Instituto de Psicologia e de Ciências da Educação, Universidade Lusíada Norte (Porto), Centro de Investigação em Psicologia para o Desenvolvimento, CIPD,

Rua Dr. Lopo de Carvalho, 4369-006, Porto, Portugal

Email address: paulomoreira@por.ulusiada.pt

\section{Abstract}

Objective(s): To fully understand the dynamics of Intimate Partner Violence (IPV) it is necessary to understand the role of personality. The current understanding of which personality characteristics are associated with IPV victimization is, however, far from comprehensive. Given this gap in the literature, our objective was to examine the associations between the dimensions of the psychobiological model of personality and psychopathological symptoms in women who had experienced IPV.

Methods: Using a case-control design, a group of women who had experienced IPV and who were living in shelters $(n=50)$ were compared to a group of control women who had not experienced IPV $(n=50)$. All women completed the Temperament and Character Inventory Revised and the Brief Symptom Inventory. 
38 Results: Victims of IPV showed significantly higher levels of Harm Avoidance and Self-

39 Transcendence, and lower levels of Reward Dependence and Self-Directedness, than the non-

40 IPV control group. Victims of IPV also reported elevated levels of psychopathological

41 symptoms. Personality dimensions showed a broadly consistent pattern of associations across

42 different psychopathological symptoms. A regression analysis indicated that Novelty Seeking

43 was negatively associated with psychopathological symptoms in victims of IPV, but not

44 significantly associated in non-victims.

45 Conclusions: The study highlights the important role of Harm Avoidance and Self-Directedness

46 for understanding psychopathological symptoms. Novelty Seeking appears to play an important

47 role in the expression of individuals' experiences of IPV. These results have important

48 implications for research and practice, particularly the development and implementation of 49 interventions.

50

51

52

53

54

55

56

57

58

59

60

61

62

63

64

65

66

67

68

\section{Introduction}

Violence occurring between family members has been broadly defined as domestic violence (Goodey, 2005). Intimate Partner Violence (IPV) refers to physical, psychological and/or sexual violence that occurs between intimate partners (including co-habiting or divorced intimate partners, independent of gender; Niolon et al., 2017). IPV is a universal phenomenon (Devries et al., 2013; O’Doherty et al., 2014), and studies have revealed high rates of violence against women in particular. Worryingly, a recent survey revealed that one in five women in the European Union has been a victim of physical and/or sexual violence by an intimate . - partner (European Union Agency for Fundamental Rights, 2014).

The experience of IPV is associated with negative psychological effects (Golding, 1999), but the type and severity of these effects may depend somewhat on a victim's personality. The present study aimed to evaluate the associations between the dimensions of the psychobiological model of personality (Cloninger, 1987; 1994) and psychopathological symptoms in women who had experienced IPV. The following subsections will present past research that describes the psychological impact of IPV and the potential influence of personality, and then introduce the psychobiological model of personality.

IPV and mental health

PeerJ reviewing PDF | (2018:12:33416:4:0:NEW 13 Feb 2019) 
70 biopsychosocial functioning. Research articles that directly address the associations between

71 IPV and mental health are less common than those that describe the physical consequences of

72 IPV (Devries et al., 2013; Van Parys, Verhamme, Temmerman \& Verstraelen, 2014).

73 Nonetheless, several influential studies have considered the impact of IPV on mental health.

74 A meta-analysis conducted by Golding (1999) reported that IPV has a significant influence

75 on victims' mental health and is a strong predictor of different types of mental disorders. The

76 negative impact of IPV on victims' psychological functioning has been confirmed more

77 recently by two independent systematic reviews (Dillon, Hussain, Loxton \& Rahman, 2013;

78 Lagdon, Armour \& Stringer, 2014). Fewer studies, however, have considered how individual

79 differences in personality dimensions serve to buffer or enhance the negative impact of IPV

80 on mental health.

81 The experience of IPV is a stressor with a strong negative impact on the various

82 biopsychological dimensions of health (Bonomi et al., 2006; Coker et al., 2002; Dillon et al.,

83 2013; Nurius \& Macy, 2010; Renner \& Whitney, 2010; Zlotnick, Johnson, \& Kohn, 2006)

84 and on the functioning of victims' children (Preto \& Moreira, 2012). The high

85 neurophysiological activation associated with abusive relationships (Okuda et al. 2011)

86 impacts on the victim's psychological functioning (Jarvis, Gordon \& Novaco, 2005; Leiner,

87 Compton, Houry, \& Kaslow, 2008) and thereby constitutes a risk factor for the development

88 of psychopathology (Golding, 1999; Hathaway et al., 2000; Pico-Alfonso et al., 2006) with

89 high levels of co-morbidity (Lagdon et al., 2014; Armour, \& Sleath, 2014). Concordantly, the

90 prevalence of mental disorders in victims of IPV is high (Lagdon et al., 2014; Okuda et al.

91 2011; Sesar, Šimić \& Dodaj, 2015). Such disorders include depression (Beydoun, Beydoun,

92 Kaufman, Lo, \& Zonderman, 2012; Sesar et al., 2015; Stein \& Kennedy, 2001), eating

93 disorders (Brady, 2008), substance abuse and addiction (Humphreys, Regan, River, \& Thiara,

94 2005; Simonelli, Pasquali, \& De Palo, 2014), anxiety (Pico-Alfonso, 2005; Simmons et al.,

95 2008), and trauma related disorders (Coker, Weston, Creson, Justice \& Blakeney, 2005).

96 Victims of IPV also present a high prevalence of schizoid personality organizations (Pérez-

97 Testor, Castillo, Davins, Salamero \& San-Martino, 2007) and paranoid, borderline and

98 schizotypal personality disorders (Khan, Welch, \& Zilmer, 1993; Pico-Alfonso, Echeburúa,

$99 \&$ Martinez, 2008). It is, therefore, of paramount importance to acquire a detailed 
100 understanding of the association between IPV and mental health in order to improve the

101 effectiveness of clinical interventions and prognoses of victims.

102 Personality and mental health

103 Personality is a strong predictor of mental health and a causal antecedent of mental disorders

104 (Cloninger, 2004). A small body of research has documented how personality influences the 105 relationship between IPV and psychosocial functioning. As an example, the experience of IPV

106 has been shown to reduce the protective effect of high education on the chances of child 107 maltreatment (Salazar, Dahlblom, Solórzano \& Herrera, 2014). However, studies describing how 108 personality characteristics are associated with the experience of IPV are scarce. As evidence of 109 this, the systematic review conducted by Lagdon et al. (2014) on the effects of experiencing IPV 110 on mental health did not include personality as a search term, and only one study included in the 111 review described personality-related dimensions (Sharhabani-Arzy, Amir \& Swisa, 2005).

112 Although all women who experience IPV are at increased risk for psychopathology, not

113 all women develop the same symptoms. Moreover, those who present the same symptoms do not 114 necessarily experience them with same severity (Nurius \& Macy, 2010). To understand a 115 victim's developmental trajectory toward resiliency/vulnerability to psychopathology after 116 experiencing IPV it is necessary to understand the personality organizations and dynamics 117 involved in biopsychological functioning (Josefsson et al., 2013). Personality dimensions are 118 linked to differences in the risk of experiencing IPV (Loas, Cormier, \& Perez-Diaz, 2011; 119 Sharhabani-Arzy et al., 2005). These dimensions also play an important role in a victim's 120 functioning, including engagement in abusive or aggressive situations (Hellmuth \& McNulty, 121 2008), failing to stop abusive relationships (Palker-Correll \& Marcus, 2004; Renner \& Slack, 122 2006; Walker, 2009), and identifying and selecting coping strategies (Connor-Smith \& 123 Flaschsbart, 2007). Personality dimensions also mediate the relationship between coping 124 strategies and psychopathology (Auerbach, Abela, Zhu \& Yao, 2010), predict positive and 125 negative aspects of health (Cloninger \& Zohar, 2010; Cloninger, Zohar \& Cloninger, 2010; 126 Dyrenforth, Kashy, Donnelan \& Lucas, 2010; Gonçalves \& Cloninger, 2010; Josefsson et al., 127 2011), and are associated with responses to trauma, including the development and recovery of 128 post-traumatic stress disorder (Kunst, 2010; North, Abbacchi, \& Cloninger, 2012). Considering 129 this evidence, it is evident that obtaining a description of the personality organizations associated 130 with IPV will prove useful for understanding the processes of change underlying the adaptive 
131 responses of victims (including those that are spontaneous, and those prompted by

132 interventions).

\section{The psychobiological model of personality}

134 The few studies to evaluate the personality of IPV victims have typically made use of the 135 Minnesota Multiphasic Personality Inventory-2, the Millon Clinical Multiaxial Inventory-I and II 136 (MCMI-II-Millon, 1987; Hart, Dutton \& Newlove, 1993), the Personality Assessment Inventory 137 (PAI; Morey, 1991; Tsang \& Stanford, 2007), and the Five-Factor Model (Hellmuth \& McNulty, 138 2008). Such studies, however, are limited by the fact they tested personality models that do not 139 facilitate an investigation of the psychobiological dynamics involved. Fortunately, the 140 psychobiological model is an integrative approach to understanding the concept of personality as 141 a non-linear developmental process within the individual (Cloninger \& Svrakic, 1997; Cloninger, 142 Svrakic, \& Przybeck, 1993; Svrakic, Whitehead, Przybeck, \& Cloninger, 1993). According to 143 this model, personality comprises two major dimensions: temperament and character. Temperament refers to the dispositional and stable tendencies to respond to basic emotional stimuli (danger, novelty and reward) with automatic habitual reactions, including inhibition, activation and behavioral maintenance (Cloninger et al., 1993). Four temperament

147 dimensions remain stable throughout an individual's development. Novelty Seeking (NS)

148 describes the tendency to respond intensely to novel stimuli as signals of pleasure. Such responses include an active approach to rewarding stimuli and active avoidance of negative stimuli. Individuals with high NS are exploratory, impulsive, and have a disliking for rules and regulations. Harm Avoidance (HA) describes the propensity to respond intensely to signals of punishment or a frustrating loss of reward by inhibiting behavior. People with high HA tend to be anxious, fearful and shy. Reward Dependence (RD) describes the tendency to respond intensely to signals of reward, especially social approval and attachment cues, and individuals with high RD are sentimental, sociable and friendly in attachments. Finally, Persistence (Ps) describes the propensity to maintain specific behaviors, despite frustration and fatigue, in anticipation of a delayed reward following prior intermittent reinforcement. High Ps is linked to eagerness, ambitiousness and perfectionism (Cloninger, 1999).

Character refers to the higher-order self-regulatory cognitive processes underlying individual differences in goals, motives, values and standards. Character consists of three dimensions that 
162 Directedness (SD) refers to the individual differences in the intrapersonal self, who is aware of 163 being an autonomous individual with motives, standards and goals. SD functions as the self164 regulatory processes in goal-oriented behaviors, meaning that individuals with high SD are 165 responsible, purposeful, resourceful and self-actualizing. Cooperativeness (C) refers to individual 166 differences in the interpersonal self, who is aware of being a member of a group in which each 167 member has rights and responsibilities. People with high $\mathrm{C}$ are tolerant, empathic, helpful, 168 principled and compassionate (Cloninger et al., 1993). Self-Transcendence (ST) refers to 169 individual differences in the transpersonal self, who is aware of being a part of a larger whole, 170 such as nature or the universe. People characterized by high ST are easily absorbed in what they 171 love to do and are altruistic and spiritual (Cloninger et al., 1993).

172 The psychobiological model of personality was initially developed for clinical assessment in 173 general and clinical populations, but has since proved to be a valid framework for describing 174 normal and abnormal human personality (Cloninger et al., 2010). The dimensions of the 175 psychobiological model of personality are causal antecedents of several indicators of mental 176 health, including psychopathology (both Axis I and Axis II conditions as proposed by the DSM177 IV-TR). Recent studies support this model's suitability for describing the personality variables 178 underlying health and all components of wellbeing, as well as ill-being, in adults (Cloninger \& 179 Zohar, 2010; Josefsson et al., 2011) and adolescents (Moreira et al., 2012; Moreira et al., 2015; 180 Schütz, Archer, \& Garcia, 2013). Thus, this model isa suitable framework from which to 181 investigate the personality characteristics of IPV victims and their associations with psychopathological symptoms.

183 With the above evidence considered, the aims of the present study were; a) to identify the 184 unique personality characteristics of women victims of IPV via a comparison with a control group who had not experienced IPV, and b) to assess whether the experience of IPV moderates the associations between personality characteristics and psychopathological symptoms.

Materials \& Methods

\section{Participants}

The study used an unmatched case-control design, allowing for the comparison of cases (women who had experienced IPV) and controls (women who had not experienced IPV). Prior to recruitment, we used a freely available online module for calculating the minimum required sample size for unmatched case-control studies (Sullivan \& Soe, 2007). For this calculation; 
194 significance level (alpha) was set at .05; power at 80\%; proportion of controls with exposure at 195 20\% (based on European Union Agency for Fundamental Rights, 2014); ratio of sample size, 196 Controls/Cases at 1:1, and proportion of cases with exposure at $80 \%$. The results indicated that a 197 minimum of 28 cases (12 cases and 14 controls) was required. Based on these results, and the 198 prevalence of IPV victims seeking support, we determined that 50 cases and 50 matched controls 199 would be an acceptable sample size. A consecutive sampling method was then used to recruit 50

200

201

202

203

204

205

206

207

208

209

210

211

212

213

214

215

216

217

218

219

220

221

222

223

224 women from specialist projects that provide support to victims of IPV. The recruitment process was conducted by a team of social workers, medical professionals, and psychologists, all of whom worked for these projects. Controls (who were women known to this team from the local community) were selected so that both groups would be approximately similar in terms of age and occupational status, although no specific matching method was used. Women were eligible to be a control if they confirmed that they had never been victims of IPV and had no formal or informal records or suspicions of IPV. All participants were from the north of Portugal where, according to a relatively recent EU-wide survey, 19\% of ever-partnered women aged 18-74 years report experiencing IPV at least once in their lifetime (European Union Agency for Fundamental Rights, 2014). This study was approved by an Internal Review Board (CIPD-2009-01) at the Research Center for Positive Development (CIPD), Portugal, and only participants who provided written informed consent where included.

\section{Instruments}

Personality. We evaluated personality dimensions using the Temperament and Character Inventory - Revised (TCI-R; Cloninger, 1999), a self-report instrument with 240 items, each scored on a 5-point Likert scale from 1 (definitely false) to 5 (definitely true). This instrument captures the four temperament (NS, HA, RD, and Ps), and three character dimensions (SD, C, and ST) of the psychobiological model of personality. Each of these scales is subdivided into between 3 and 5 subscales that capture different aspects of each personality dimension. The Portuguese version of the TCI-R, which we used in this study, has shown good psychometric properties in the Portuguese population (Moreira et al., 2017).

Psychopathology symptoms. To evaluate psychopathology, we used the Portuguese version of the Brief Symptom Inventory (BSI; Derogatis \& Spencer, 1982). This instrument consists of 53 items that assess 9 dimensions of psychopathology symptoms. Items are scored using a 5-point Likert scale ranging from 0 (never) to 4 (many times). The 9 symptom 
225 dimensions are: Somatization, Obsession-Compulsion, Interpersonal Sensitivity, Depression,

226 Anxiety, Hostility, Phobic anxiety, Paranoid ideation and Psychoticism. The Portuguese version 227 of the BSI (Canavarro, 1999) has been shown to have acceptable psychometric properties, with 228 alpha values that vary between .62 (Psychoticism) and .80 (Somatization).

\section{Procedures}

230 Data collection procedures. The psychologists, social workers and medical

231 professionals working for the support projects collaborated in the collection of data for the IPV 232 group. Prior to data collection, the study aims were explained to participants (individually) and 233 informed consents were obtained. Participants in the IPV group completed both questionnaires

234 (paper format) in a technician's office. Participants in the non-IPV completed the questionnaires 235 in an office in the community. For both groups, the order in which we presented the two 236 questionnaires (TCI-R and BSI) was counterbalanced to control for possible order effects.

237 Participants took approximately 1 hour to complete the questionnaires.

238 Data analysis. We used statistical methods appropriate for non-matched case-control 239 designs given that we did not use a specific matching procedure to pair cases with controls 240 (instead groups were roughly equated based on age and occupational status). First, group 241 differences based on demographic variables were assessed. For categorical demographic 242 variables -- civil status (married, single, divorced or other), occupation status, education level 243 (less than secondary school, secondary school or above secondary school), and violence type 244 (psychological, psychological + physical or psychological + physical + sexual) -- group 245 differences were assessed using Cramer's V. Differences in age were assessed using an 246 independent samples t-test. Because cases and controls were statistically different for one of 247 these variables (education level), we tested the main effect of group for each personality 248 dimension and psychopathology symptoms using a series of ANCOVAs. For these analyses, 249 education level was included as a covariate. To assess the associations between dimensions of 250 personality and psychopathological symptoms in victims of IPV we calculated Pearson's 251 correlations between TCI-R and BSI subscales. This correlational analysis was only applied to 252 the IPV group $(n=50)$. We interpreted the effect size of correlation coefficients in accordance 253 with the guidelines offered by Cohen (1988). Finally, we conducted a series of linear multiple 254 regression analyses, using the entire sample $(n=100)$, to assess whether the experience of IPV 
255 interacts with personality dimensions in explaining variance in total symptoms. For these

256 analyses, personality dimensions and IPV (coded as a dummy variable) were mean centered.

\section{Results}

258 Demographic statistics

259 Table 1 presents the demographic characteristics of the study participants. Participants in the IPV 260 group had significantly lower education levels than participants in the non-IPV group, with none 261 of the IPV group achieving higher than a secondary-school level of education (Cramer's V= $2620.45, p<.001)$. There were no significant differences between groups in terms of age, civil 263 status, or occupation status. The majority of the IPV group suffered a combination of physical 264 and psychological violence $(62 \%)$.

\section{Differences in personality dimensions}

266 Figure 1 presents personality profiles for the IPV and non-IPV groups. In order to standardize 267 scores across the different personality dimensions, Figure 1 presents z scores (representing the 268 number of standard deviations from mean). The IPV group was characterized by elevated Harm 269 Avoidance and Self-Transcendence, and lower Novelty Seeking, Reward Dependence, 270 Persistence, Self-Directedness and Cooperativeness compared to the non-IPV group. Next, we 271 conducted a series of ANCOVAs (based on raw scores) to assess the significance of these 272 observed differences after controlling for group differences in education (see Table 2). These 273 analyses indicated that the largest observed effect of group was for Self-Directedness: the IPV 274 group had significantly lower Self-Directedness than the non-IPV group $(F=13.44, p<.001)$. 275 Women victims of IPV also presented significantly lower levels of Reward Dependence $(F=$ 276 7.52, $p=.007)$, and significantly higher levels of Harm Avoidance $(F=5.52, p=.021)$ and Self277 Transcendence $(F=7.90, p=.006)$.

\section{Differences in psychopathology symptoms}

279 Figure 2 presents the mean summed scores of the BSI symptom subscales for the IPV and non280 IPV groups. A series of ANCOVAs (see Table 3) indicated that participants in the IPV group 281 had significantly higher levels of all symptoms. The largest effect of group across all symptoms, 282 after controlling for differences in education, was observed for depression $(F=45.43, p<.001)$. 283 Correlations between personality dimensions and psychopathological symptoms in victims 284 of IPV 
285 The pattern of correlations across symptom dimensions was broadly consistent for each 286 personality dimension in the IPV group (see Tables 4 and 5). Medium-sized $(|.50|>r>|.30|$; 287 Cohen, 1988) correlations were found between Novelty Seeking and psychoticism $(r=-.42)$; 288 between Self-Directedness and hostility $(r=-.41)$, paranoid ideation $(r=-.45)$ and psychoticism $289(r=-.50)$; and between Self-Transcendence and interpersonal Sensitivity $(r=-.43)$. Harm 290 Avoidance was the only temperament dimension positively correlated with psychopathology 291 symptoms: paranoid ideation $(r=.46)$, psychoticism $(r=.43)$ and interpersonal sensitivity $(r=$ $292.41)$.

293 The moderating effect of IPV on the association between personality and 294 psychopathological symptoms

295 296

297

298

299

300

301

302

303

304

305

306

307

308

309

310

311

312

313

314

315

A correlational analysis indicated that total symptoms were significantly correlated with education level $(r=-.25, p=.011)$ and type of IPV $(r=.54, p<.001)$, and consequently these variables were included as covariates in the following regression models. Age was not significantly correlated with total symptoms in our sample $(r=.03)$, although we also included this variable as a covariate given that prior research has shown clear age effects on psychopathology (e.g. Erskine, Kvavilashvili, Conway \& Myers, 2007).

Table 6 presents the results of seven independent regression analyses. After controlling for the effect of IPV, education level, age, and violence type, Harm Avoidance $(b=.75, p<$ $.001)$ and Self-Directedness $(b=-.67, p<.001)$ were significant predictors of total symptoms in their respective models. Crucially, while Novelty Seeking was not a significant predictor of symptoms, it was found to have a significant interaction with IPV $(b=-1.10, p=.034)$. This interaction is plotted in Figure 3. (Note that we used z scores for Novelty Seeking and raw scores for total symptoms to graph this significant interaction). The simple slopes for this interaction indicated that there was a non-significant positive relationship between Novelty Seeking and total symptoms in the non-IPV controls, $b=.25,95 \% \mathrm{CI}[-0.51,1.00]$, and a significant negative relationship between Novelty Seeking and total symptoms in victims of IPV, $b=-.85$, 95\% CI [$1.53,-0.17]$. IPV did not interact with the remaining six personality dimensions in the prediction of psychopathology symptoms.

\section{Discussion}

14 The principle finding of this study was that women victims of IPV had a significantly different

15 character and temperament profile to a group of control women who had reported never 
316 experiencing IPV. The results also show that personality dimensions were differentially 317 associated with psychopathology symptoms in victims of IPV, and that the experience of IPV 318 moderated the association between Novelty Seeking and total symptoms. The following 319 discussion will address these findings in turn.

320 IPV and personality characteristics

321 The IPV group had a character configuration of low Self-Directedness, low Cooperativeness, and 322 high Self-Transcendence (a $s c T$ configuration). In terms of temperament, these women had high 323 levels of Harm Avoidance, and low scores in Novelty Seeking, Reward Dependence and 324 Persistence: an $n H r p$ configuration. These personality configurations (Cloninger et al., 1993) 325 imply that these women were more likely to be immature, disorganized, and schizotypal 326 (associated with $s c T$ configuration), and to have weak social skills and avoidant behavior 327 (associated with $n H r p$ configuration). These character and temperament features are typical of 328 psychological organizations associated with schizotypal personality disorder (Cloninger, Bayon, 329 \& Svrakic, 1998; Svrakic et al., 2002), one of the most dominant personality disorders in this 330 population (Pérez-Testor et al., 2007; Pico-Alfonso et al., 2008).

331 If the personality characteristics associated with the IPV group are considered as 332 antecedent causes of individual differences (indeed studies have demonstrated personality 333 dimensions have predictive validity in prospective studies; Grucza \& Goldberg, 2007), our 334 results imply that women inherently more tolerant of routine and conformity, and less willing to 335 explore new situations are more vulnerable to IPV. Low levels of Novelty Seeking may account 336 for a higher tolerance to repeated patterns of abusive interactions and may partially account for 337 the difficulties many women have in leaving abusive relationships (Cloninger et al. 1993). The 338 IPV group also showed high levels of Harm Avoidance -- indeed significantly higher Harm 339 Avoidance than the non-IPV group -- a trait associated with high levels of negative affectivity 340 (Cloninger et al., 1993). Negative emotions have been shown to interfere with executive 341 functioning (Ochsner et al., 2004) and this may influence the ability of IPV victims to conceive 342 of, plan, and then actively seek new experiences (i.e. new relationships). The significantly lower 343 levels of Reward Dependence found in the IPV group compared to the non-IPV group also 344 implies that these women are dispositionally more tolerant of the lack of warm and secure 345 emotional reward from abusive relationships. These findings are consistent with past evidence 346 about the indicators of the biopsychosocial functioning of victims. Neuroticism, as defined by 
347 the Five-Factor model of personality, corresponds to high Harm Avoidance and low Self-

348 Directedness in the psychobiological model (Cloninger, 2006). This pattern of high Harm

349 Avoidance and low Self-Directedness was characteristic of the IPV group in our study.

350 Neuroticism (both in victims and in the aggressor) is as a major predictor of starting/precipitating

351 the aggressive situations of IPV (Hellmuth \& McNulty, 2008).

352 Thus far, we have discussed the present results in terms of how personality may increase

353 vulnerability to IPV. As with all correlational data, our results might equally demonstrate the

354 association between IPV and stress-related personality changes. In support of this proposal,

355 longitudinal research has shown that the experience of traumatic events in adulthood can cause

356 changes to personality (Josefsson et al., 2013) including increases in neuroticism (high Harm

357 Avoidance and low Self-Directedness) and decreases in agreeableness (Löckenhoff, Terracciano,

358 Patriciu, Eaton, \& Costa, 2009). Consequently, some care should be taken before drawing the

359 conclusion that individuals with certain personality profiles are at increased risk of suffering

360 IPV.

361 Personality and psychopathology

362 Personality influences the nature, intensity and frequency of exposure to stress factors. This

363 interferes with the coping strategies used by the individuals in stressful situations (Connor-Smith

$364 \&$ Flachsbart, 2007). The selection and use of coping strategies has been shown to be correlated

365 with several Big Five personality dimensions, and in particular, neuroticism has been linked to

366 less adaptive strategies (Connor-Smith \& Flaschsbart, 2007). The low Novelty Seeking, low

367 Reward Dependence, low Persistence, low Self-Directedness and high Harm Avoidance found in

368 our IPV group (which corresponds closely to neuroticism) therefore implies that victims may not

369 use adequate or adaptive problem-solving and cognitive restructuring strategies (Connor-Smith

$370 \&$ Flachsbart, 2007). The elevation of Self-Transcendence found in victims of IPV is also likely

371 to be related to the coping skills necessary for dealing with daily suffering (Coward \& Reed,

372 1996).

373 Past studies have demonstrated that personality has an influence on psychopathology via

374 its effect on coping strategies (Auerbach et al., 2010), a finding which is consistent with the

375 elevation of psychopathology in our IPV group. High Harm Avoidance is a strong predictor of

376 the presence and severity of anxiety and mood disorders (Cloninger et al., 2010; Gonçalves \&

377 Cloninger, 2010) because it potentiates the impact of negative life events and hinders the 
378 development of adaptive coping strategies (Hofmann \& Bitran, 2007). Individuals with high 379 Harm Avoidance tend to be highly sensitivity to negative life events and have difficulty dealing 380 with their impact (Cole, Logan, \& Shannon, 2005). Such characteristics may contribute to the 381 high prevalence of psychopathology in victims of IPV (Howard et al., 2010; Nurius \& Macy, 382 2010; Okuda et al., 2011) and their difficulty in stopping abusive relationships (Palker-Correll \& 383 Marcus, 2004; Renner \& Slack, 2006; Walker, 2006). In addition, the character dimensions Self384 Directedness and Cooperativeness (which were low in our IPV sample) are predictors of a range 385 of positive indicators of health, including subjective wellbeing (Cloninger \& Zohar, 2010; 386 Josefsson et al., 2013). Such associations may help explain the low levels of satisfaction in life 387 (Dyrenforth et al., 2010), low quality of life (Adeodato, Carvalho, de Siqueira \& Matos, 2005), 388 and the high psychological distress and suicidality (Leiner et al., 2008) among victims of IPV. 389 Finally, personality dimensions have been shown to predict the development of severe conditions 390 after trauma (such as PTSD; North et al. 2012), to mediate the relationship between depression and PTSD (Bargai, Ben-Shakhar \& Shalev, 2007), and to predict recovery from PTSD in victims 392 (Kunst, 2010). High levels of Self-Directedness and Cooperativeness are a protective factor 393 against the development of PTSD (North et al., 2012). Moreover, a positive affect type of 394 395 personality (low Harm Avoidance and high Self-Directedness) predicts recovery from PTSD among victims.

The final major finding of the present study, in addition to highlighting the important role of Harm Avoidance and Self-Directedness for understanding psychopathological symptoms, was the significant interaction between Novelty Seeking and IPV. Specifically, high Novelty Seeking 399 in women victims of IPV was linked to fewer total symptoms, while high Novelty Seeking in the control group was related to elevated total symptoms. Novelty Seeking thus appears to plays an important role in the expression of individuals' experiences of IPV via the manifestation of psychopathological symptoms. It is important to highlight that symptoms from affective domains 403 (depression and anxiety), elsewhere referred to as internalizing symptoms, are a prevalent feature in individuals with elevated Harm Avoidance, such is the case in women victims of IPV. High Novelty Seeking refers to a behavioral phenotype of sensitivity to novelty that expresses as

406 higher openness to new experiences and a tendency to externalize internal states. High sensitivity 407 to novelty, and in particularly higher openness to new experience, implies that women with high 408 Novelty Seeking express an intolerance for monotony and may be more easily provoked to a 
409 fight or flight response (Cloninger, 1987). Such women may have a stronger drive to explore 410 alternatives to their abusive relationships. Individuals high in Novelty Seeking are also more 411 likely to interact with their environments by externalizing their subjective experiences (both 412 positive and negative), and this can manifest as impulsive overt expressions of feelings, thoughts 413 and internal states. These impulsive overt expressions can serve as important signals about an 414 individual's subjective experience, and can function as a boundary setter and/or a sign of 415 empowerment within an abusive relationship. Moreover, overt expressions of internal states to 416 individuals outside of the relationship can be an important coping mechanism.

417 Past research has shown that effective interventions for IPV victims promote the 418 development of internal resources and strengths, particularly personal agency mechanisms and 419 socio-cognitive processes (e.g. Burnette \& Cannon, 2014; Hansen, Eriksen, \& Elklit, 2014; 420 Hoyeck, Madden, Freeman, Scott, \& Bhandari, 2014). Results from studies on change processes 421 (both spontaneous and intervention-promoted) in IPV victims converge on the finding that the 422 psychobiological processes associated with change are well captured by personality dimensions. 423 Processes such as self-esteem and self-efficacy, reflection, awareness, meaning making, or self424 identity are components of higher-order dimensions such the individuals' systems of beliefs, 425 standards and goals. These in turn refer to crucial dimensions of personality, as is revealed by 426 their inclusion in many theories of personality. For example, an individual's systems of beliefs, 427 standard and goals refer to the dimensions of character in Cloninger's psychobiological model of 428 personality (Cloninger, Svrakic, \& Przybeck, 1993).

\section{Limitations:}

430 Some limitations of the present study require consideration. Firstly, we used a cross-sectional 431 design and were therefore unable to draw any conclusions about how personality might change 432 over time because of IPV. Further, the way we analyzed the associations between personality 433 dimensions and psychopathology (correlational) means that the reader should be wary of 434 inferring causality. Future investigations should use appropriate regression analyses and 435 longitudinal designs if aiming to understand whether personality characteristics serve as 436 antecedents to psychopathology. It should be noted that for such analyses a larger sample size 437 than the one used in this study would be required to achieve sufficient power. Another limitation to consider is that victims of IPV were recruited from specialist projects. The implication of this aspect of the design is that our sample is unlikely to be fully 
440 representative of all women victims of IPV. Women seeking support from specialist projects are 441 likely to represent only the most serious experiences of IPV, and will not include the large 442 number of women who conceal their victimization. Furthermore, women who do reveal their 443 experiences of IPV and seek or accept help from such projects may have specific personality 444 profiles that are not representative of all victims. Consequently, the personality profile for IPV 445 victims identified in our study may correspond to a specific subsample of women victims. Future 446 studies with alternative sampling techniques will be required to verify our findings.

447 A final limitation of this study is that we did not collect data for variables that might 448 mediate the relationship between high Harm Avoidance, low Self-Directedness and involvement 449 in violence, and thus did not control for them. Future studies should therefore control variables 450 such as alcohol abuse (Egan \& Hamilton, 2008), effective problem-solving skills, levels of 451 experienced stress (Hellmuth \& McNulty, 2008), satisfaction with life (Dyrenforth et al., 2010), 452 and history of maltreatment in childhood or characteristics of abuse (Bensley, van Eenwyk \& 453 Simmons, 2003).

454

455 Conclusions

456 Our study highlights of the relevance of personality dimensions for understanding the experience 457 of being a victim of IPV. Harm Avoidance and Self-Directedness are of particular importance for 458 understanding an individual's risk for experiencing psychopathological symptoms. Novelty 459 Seeking appears to play an important role in the expression of individuals' experiences of IPV. 460 These results have important implications for research and practice (especially for the 461 development and implementation of interventions). Specifically, they suggest that the personality 462 of each IPV victims needs to be considered when planning interventions and practices, from 463 crisis interventions to medium- and long-term interventions. Indeed, corresponds to a major 464 challenge in current mental health services: shifting from an emphasis on symptoms to a person465 centered approach to individuals. 
470 471

472

473 474 475 476 477 478 479 480 481 482 483 484 485 486 487 488 489 490 491 492 493 494 495 496 497 498 499 500

Adeodato, V. G., Carvalho, R. R., de Siqueira, V. R., \& de Matos, F. G. (2005). Quality of life and depression in women abused by their partners. Revista de Saúde Pública, 39(1), 108113. doi:10.1590/S0034-89102005000100014

Armour, C., \& Sleath, E. (2014). Assessing the co-occurrence of intimate partner violence domains across the life-course: Relating typologies to mental health. European Journal of Psychotraumatology, 5(1), 24620. doi:10.3402/ejpt.v5.24620

Auerbach, R. P., Abela, J. R. Z., Zhu, X. \& Yao, S. (2010). Understanding the role of coping in the development of depressive symptoms: Symptom specificity, gender differences, and cross-cultural applicability. British Journal of Clinical Psychology, 49(4), 47-561. doi:10.1348/014466509X479681

Bargai, N., Ben-Shakhar, G., \& Shalev, A. Y. (2007). Posttraumatic stress disorder and depression in battered women: The mediating role of learned helplessness. Journal of Family Violence, 22(5), 267-275. doi:10.1007/s10896-007-9078-y

Bensley, L., van Eenwyk, J., \& Simmons, W. K. (2003). Childhood family violence history and women's risk for intimate partner violence and poor health. American Journal of Preventive Medicine, 25(1), 38-44. doi:10.1016/S0749-3797(03)00094-1

Beydoun, H. A., Beydoun, M. A., Kaufman, J. S., Lo, B., \& Zonderman, A. B. (2012). Intimate partner violence against adult women and its association with major depressive disorder, depressive symptoms and postpartum depression: A systematic review and meta-analysis. Social Sciences and Medicine, 75(6), 959-975. doi:10.1016/j.socscimed.2012.04.025

Bonomi, A. E., Thompson, R. S., Anderson, M., Reid, R. J., Carrell, D., Dimer, J. A., \& Rivara, F. P. (2006). Intimate partner violence and women's physical, mental, and social functioning. American Journal of Preventive Medicine, 30(6), 458-466. doi:10.1016/j.amepre.2006.01.015

Brady, S. S. (2008). Lifetime family violence exposure is associated with current symptoms of eating disorders among both young men and women. Journal of Traumatic Stress, 21(3), 347-351. doi:10.1002/jts.20335

Burnette, C. E., \& Cannon, C. (2014). "'It will always continue unless we can change something', Consequences of intimate partner violence for indigenous women, children, and families. European Journal of Psychotraumatology, 5(1), 24585. doi:10.3402/ejpt.v5.24585 
501 Canavarro, M. C. (1999). Inventário de sintomas psicopatológicos -BSI. In M. R. Simões, M.

502 Gonçalves \& L. S. Almeida (Eds.), Testes e Provas Psicológicas em Portugal (vol. II). 503 Braga: APPORT/SHO.

504 Centers for Disease Control and Disease (2016). Intimate Partner Violence: Definitions.

$505 \quad$ Retrieved April, 2016, from

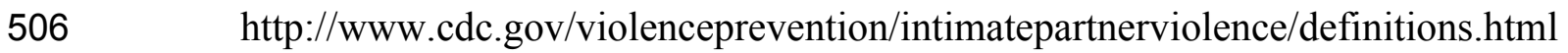

507 Cloninger C. R. (2006). Personality as a dynamic psychobiological system. In T. A.Widiger, E.

508

509

510

511

512

513

514

515

516

517

518

519

520

521

522

523

524

525

526

527

528

529

530

Simonsen, P. J. Sirovatka, \& D. A. Regier (Eds). Dimensional Models of Personality Disorders: Refining the Research Agenda for DSM-V (pp. 73-76). Washington, DC: American Psychiatric Press.

Cloninger, C. R. (1987). A systematic method for clinical description and classification of personality variants. Archives of General Psychiatry, 44(6), 573-588.

doi:10.1001/archpsyc.1987.01800180093014

Cloninger, C.R. (1994). Temperament and personality. Current Opinion in Neurobiology, 4(2), 266-273.

Cloninger, C. R. (1999). The Temperament and Character Inventory-Revised. St. Louis, MO: Center for Psychobiology of Personality, Washington University.

Cloninger, C. R. (2004). Feeling Good: The science of wellbeing. Washington: Oxford University Press.

Cloninger, C. R., \& Svrakic, D. M. (1997). Integrative psychobiological approach to psychiatric assessment and treatment. Psychiatry, 60(2), 120-141.

doi:10.1080/00332747.1997.11024793

Cloninger, C. R., Bayon, C., \& Svrakic, D. M. (1998). Measurement of temperament and character in mood disorders: A model of fundamental states as personality types. Journal of Affective Disorders, 51(1), 21-32. doi:10.1016/s0165-0327(98)00153-0

Cloninger, C. R., Svrakic, D. M., \& Przybeck, T. R. (1993). A psychobiological model of temperament and character. Archives of General Psychiatry, 50(12), 975-990. doi:10.1001/archpsyc.1993.01820240059008

Cloninger, C. R., Zohar, A. H., \& Cloninger, K. M. (2010). Promotion of well-being in personcentered mental health care. FOCUS, 8(2), 165-179. doi:10.1176/foc.8.2.foc1653 
531 Cloninger, C. R. \& Zohar, A. H. (2010). Personality and the perception of health and happiness.

532

533

534

535

536

537

538

539

540

541

542

543

544

545

546

547

548

549

550

551

552

553

554

555

556

557

558

559

560

561

Journal of Affective Disorders, 128(1-2), 24-32. doi:10.1016/j.jad.2010.06.012

Cohen, J. (1988). Statistical power analysis for the behavioral sciences. Hillsdale, NJ: Erlbaum.

Coker, A. L., Weston, R., Creson, D. L., Justice, B., \& Blakeney, P. (2005). PTSD Symptoms among men and women survivors of intimate partner violence: The role of risk and protective factors. Violence and Victims, 20(6), 625-643. doi:10.1891/vivi.20.6.625

Coker, A. L., Davis, K. E., Arias, I., Desai, S., Sanderson, M., Brandt, H. M., \& Smith, P. H. (2002). Physical and mental health effects of intimate partner violence for men and women. American Journal of Preventive Medicine, 23(4), 260-268. doi:10.1016/S07493797(02)00514-7

Cole, J., Logan, T., \& Shannon, L. (2005). Intimate sexual victimization among women with protective orders: Types and associations of physical and mental health problems. Violence and Victims, 20(6), 695-715. doi:10.1891/vivi.20.6.695

Connor-Smith, J. K. \& Flachsbart, C. (2007). Relations between personality and coping: A metaanalysis. Journal of Personality and Social Psychology, 93(6), 1080-1107. doi:10.1037/0022-3514.93.6.1080

Coward, D. D., \& Reed, P. G. (1996). Self-Transcendence: A resource for healing at the end of life. Issues in Mental Health Nursing, 17(3), 275-288. doi:10.3109/01612849609049920

Derogatis, L. R., \& Spencer, P. M. (1982). Administration and procedures: BSI. Manual I. Baltimore, MD: Clinical Psychometric Research.

Devries, K. M., Mak, J. Y., Garcia-Moreno, C., Petzold, M., Child, J. C., Falder, G., Lim, S., Bacchus, L. J., Engell, R. L., Rosenfeld, L., Pallitto, C., Vos, T., Abrahams, N., \& Watts, C.H. (2013). Global health. The global prevalence of intimate partner violence against women. Science, 340(6140), 1527-1528. doi:10.1126/science.1240937

Dillon, G., Hussain, R., Loxton, D., \& Rahman, S. (2013). Mental and physical health and intimate partner violence against women: A review of the literature. International Journal of Family Medicine, 2013, 1-15. doi:10.1155/2013/313909

Dyrenforth, P. S., Kashy, D. A., Donnellan, M. B. \& Lucas, R. E. (2010). Predicting relationship and life satisfaction from personality in nationally representative samples from three countries: The relative importance of actor, partner, and similarity effects. Journal of Personality and Social Psychology, 99(4), 690-702. doi:10.1037/a0020385 
562 Egan, V. \& Hamilton, E. (2008). Personality, mating effort and alcohol-related violence

563

564

565

566

567

568

569

570

571

572

573

574

575

576

577

578

579

580

581

582

583

584

585

586

587

588

589

590

591 expectancies. Addiction Research and Theory, 16(4), 369-381. doi:10.1080/16066350701850717

Erskine, J.A.K., Kvavilashvili, L., Conway, M.A., \& Myers, L. (2007). The effects of age on psychopathology, well-being and repressive coping. Aging \& Mental Health, 11(4), 394404. doi:10.1080/13607860600963737

European Union Agency for Fundamental Rights. (2014). Violence against women: An EUwide survey. Luxembourg: Publications Office of the European Union.

Faul, F., Erdfelder, E., Lang, A.-G., \& Buchner, A. (2007). G*Power 3: A flexible statistical power analysis program for the social, behavioral, and biomedical sciences. Behavior Research Method, 39(2), 175-191. doi:10.3758/bf03193146

Golding, J. M. (1999). Intimate partner violence as a risk factor for mental disorders: A metaanalysis. Journal of Family Violence, 14(2), 99-131. doi:10.1023/A:1022079418229

Gonçalves, D. M., \& Cloninger, C. R. (2010). Validation and normative studies of the Brazilian Portuguese and American versions of the Temperament and Character Inventory Revised (TCI-R). Journal of Affective Disorders, 124(1-2), 126-133. doi:10.1016/j.jad.2009.11.007

Gonçalves, M. M., Matos, M., \& Santos, A. (2009). Narrative therapy and the nature of "innovative moments" in the construction of change. Journal of Constructivist Psychology, 22(1), 1-23. doi:10.1080/10720530802500748

Gonçalves, M. M., Ribeiro, P. A., Mendes, I., Matos, M., \& Santos, A. (2011). Tracking novelties in psychotherapy process research: The innovative moments coding system. Psychotherapy Research, 21(5), 497-509. doi:10.1080/10503307.2011.560207

Goodey, J. (2005). Victims and victimology: Research, policy and practice. Pearson Education.

Grucza, R. A., \& Goldberg, L. R. (2007). The comparative validity of 11 modern personality inventories: predictions of behavioral acts, informant reports, and clinical indicators. Journal of Personality Assessment, 89(2), 167-187. doi:10.1080/00223890701468568

Hansen, N. B., Eriksen, S. B., \& Elklit, A. (2014). Effects of an intervention program for female victims of intimate partner violence on psychological symptoms and perceived social 
592

593

594

595

596

597

598

599

600

601

602

603

604

605

606

607

608

609

610

611

612

613

614

615

616

617

618

619

620

621

support. European Journal of Psychotraumatology, 5(1), 24797.

doi:10.3402/ejpt.v5.24797

Hart, S. D., Dutton, D. A., \& Newlove, T. (1993). The prevalence of personality disorder among wife assaulters. Journal of Personality Disorders, 7(4), 329-341. doi:10.1521/pedi.1993.7.4.329

Hathaway, J. E., Mucci, L. A., Silverman, J. G., Brooks, D. R., Mathews, R., \& Pavlos, C. A. (2000). Health status and health care use of Massachusetts women reporting partner abuse. American Journal of Preventive Medicine, 19(4), 302-307. doi:10.1016/s07493797(00)00236-1.

Hellmuth, J.C. \& McNulty, J.K. (2008). Neuroticism, marital violence and the moderating role of stress and behavior skills. Journal of Personality and Social Psychology, 95(1), 166180. doi:10.1037/0022-3514.95.1.166

Hofmann, S. G., \& Bitran, S. (2007). Sensory-processing sensitivity in social anxiety disorder: relationship to harm avoidance and diagnostic subtypes. Journal of Anxiety Disorders, 21(7), 944-954. doi:10.1016/j.janxdis.2006.12.003

Howard, L. M., Trevillion, K., Khalifeh, H., Woodall, A., Agnew-Davies, R., \& Feder, G. (2010). Domestic violence and severe psychiatric disorders: Prevalence and interventions. Psychological Medicine, 40(6), 881-893. doi:10.1017/S0033291709991589

Hoyeck, P., Madden, K., Freeman, C., Scott, T., \& Bhandari, M. (2014). Predictors of change in mental health and distress among women attending a women's shelter. European Journal of Psychotraumatology, 5, 24809. doi:10.3402/ejpt.v5.24809

Humphreys, C., Regan, L., River, D., \& Thiara, R. K. (2005). Domestic violence and substance use: Tackling complexity. British Journal of Social Work, 35(8), 1303-1320. doi:10.1093/bjsw/bch212

Jarvis, K. L., Gordon, E. E. \& Novaco, R. W. (2005). Psychological distress of children and mothers in domestic violence emergency shelters. Journal of Family Violence, 20(6), 389-402. doi:10.1007/s10896-005-7800-1

Josefsson, K., Jokela, M., Cloninger, C.R., Hintsanen, M., Salo, J., Hintsa, T., Pulkki-Råback, L., \& Keltikangas-Järvinen, L. (2013). Maturity and change in personality: developmental 
622

623

624

625

626

627

628

629

630

631

632

633

634

635

636

637

638

639

640

641

642

643

644

645

646

647

648

649

650

651

652

trends of temperament and character in adulthood. Development and Psychopathology, 25(3), 713-727. doi:10.1017/S0954579413000126

Josefsson, K., Cloninger, C.R., Hintsanen, M., Jokela, M., Pulkki-Råback, L., \& KeltikangasJärvinen, L. (2011). Associations of personality profiles with various aspects of wellbeing: a population-based study. Journal of Affective Disorders, 133(1), 265-273. doi:10.1016/j.jad.2011.03.023

Khan, F. I., Welch, T. L., \& Zilmer, E. A. (1993). MMPI-2 profiles of battered women in transition. Journal of Personality Assessment, 60(1), 100-111. doi:10.1207/s15327752jpa6001_7

Kunst, M. J. J. (2010). Affective personality type, post-traumatic stress disorder symptom severity and post-traumatic growth in victims of violence. Stress \& Health, 27(1), 42-51. doi:10.1002/smi. 1318

Lagdon, S., Armour, C., \& Stringer, M. (2014). Adult experience of mental health outcomes as a result of intimate partner violence victimisation: a systematic review. European Journal of Psychotraumatology, 5(1), 24794 doi:10.3402/ejpt.v5.24794.

Leiner, A. M., Compton, M. T. Houry, D., \& Kaslow, N. J. (2008). Intimate partner violence, psychological distress, and suicidality: A path model using data from African American women seeking care in an urban emergency department. Journal of Family Violence, 23(6), 473-481. doi:10.1007/s10896-008-9174-7

Loas, G., Cormier, J., \& Perez-Diaz, F. (2011). Dependent personality disorder and physical abuse. Psychiatry Research, 185(1-2), 167-170. doi:10.1016/j.psychres.2009.06.011

Löckenhoff, C. E., Terracciano, A., Patriciu, N. S., Eaton, W. W., \& Costa, P. T., Jr. (2009). Self-reported extremely adverse life events and longitudinal changes in five-factor model personality traits in an urban sample. Journal of Traumatic Stree, 22(1), 53-59. doi:10.1002/jts.20385

Matos, M., Santos, A., Pinheiro, P., \& Lourenço, P. (2016). Multiply victimized women: How do they change? Journal of Constructivist Psychology, 29(4), 432-446. doi:10.1080/10720537.2015.1114437

Millon, T. (1987). Manual for Millon Clinical Multiaxial Inventory II (MCMI-II). Minneapolis, MN: National Computer Systems. 
653 Moreira, P. A. S., Cloninger, C. R., Rocha, M. J., Ferreira, N., Oliveira, J. \& Gonçalves, D. M.

654

655

656

657

658

659

660

661

662

663

664

665

666

667

668

669

670

671

672

673

674

675

676

677

678

679

680

681

682

683 (2017). The psychometric properties of the Portuguese version of the TCI-R. Psychological Reports, 120(6) 1178-1199. doi:10.1177/0033294117711914

Moreira, P. A. S, Cloninger, C. R., Dinis, L., Sá, L, Oliveira, J. T., Dias, A., \& Oliveira, J. (2015) Personality and well-being in adolescents. Frontiers in Psychology, 5, 1494. doi:10.3389/fpsyg.2014.01494

Moreira, P. A. S., Oliveira, J. T., Cloninger, K. M., Azevedo, C., Sousa, A., Castro, J. \& Cloninger, C. R. (2012). The Psychometrics and validity of the Junior Temperament and Character Inventory in Portuguese adolescents. Comprehensive Psychiatry, 53(8), 1227-1236. doi:10.1016/j.comppsych.2012.04.014

Morey, L. C. (1991). Personality assessment inventory. Odessa, FL: Psychological Assessment Resources.

Niolon, P. H., Kearns, M., Dills, J., Rambo, K., Irving, S., Armstead, T., \& Gilbert, L. (2017). Preventing intimate partner violence across the lifespan: A technical package of programs, policies, and practices. Atlanta, GA: National Center for Injury Prevention and Control, Centers for Disease Control and Prevention.

North, C. S., Abbacchi, A., \& Cloninger, C. R. (2012). Personality and posttraumatic stress disorder among directly exposed survivors of the Oklahoma City bombing. Comprehensive Psychiatry, 53(1), 1-8. doi:10.1016/j.comppsych.2011.02.005

Nurius, P. S. \& Macy, R. C. (2010). Person-oriented methods in partner violence research: Distinct biopsychosocial profiles among battered women. Journal of Interpersonal Violence, 25(6), 1064-1093. doi:10.1177/0886260509340541

Ochsner, K. N., Ray, R. D., Cooper, J. C., Robertson, E. R., Chopra, S., Gabrieli, J. D., \& O’Doherty, L. J., Taft, A., Hegarty, K., Ramsay, J., Davidson, L. L., \& Feder, G. (2014). Screening women for intimate partner violence in healthcare settings: abridged Cochrane systematic review and meta-analysis. British Medical Journal, 348, g2913. doi:10.1136/bmj.g2913

Okuda, M., Olfson, M., Hasin, D., Grant, B. F., Lin, K-H. \& Blanco, C. (2011). Mental health of victims of intimate partner violence: Results from a national epidemiologic survey. Psychiatric Services, 62(8), 959-962. doi:10.1176/appi.ps.62.8.959 
684 Palker-Correll, A., \& Marcus, D. K. (2004). Partner abuse, learned helplessness, and trauma

685

686

687

688

689

690

691

692

693

694

695

696

697

698

699

700

701

702

703

704

705

706

707

708

709

710

711

712

713

714 symptoms. Journal of Social and Clinical Psychology, 23(4), 445-462. doi:10.1521/jscp.23.4.445.40311

Pérez-Testor, C., Castillo, J. A., Davins, M., Salamero, M., \& San-Martino, M. (2007). Personality profiles in a group of battered women: Clinical and care implications. Journal of Family Violence, 22(2), 73-80. doi:10.1007/s10896-006-9057-8

Pico-Alfonso, M., Garcia-Linares, M. I., Celda-Navarro, N., Blasco-Ros, C., Echeburúa, E., \& Martinez, M. (2006). The impact of physical, psychological, and sexual intimate male partner violence on women's mental health: depressive symptoms, posttraumatic stress disorder, state anxiety, and suicide. Journal of Women's Health, 15(5), 599-611. doi:10.1089/jwh.2006.15.599

Pico-Alfonso, M. A. (2005). Psychological intimate partner violence: The major predictor of posttraumatic stress disorder in abused women. Neuroscience and Biobehavioral Reviews, 29(1), 181-193. doi:10.1016/j.neubiorev.2004.08.010

Pico-Alfonso, M. A., Echeburúa, E., \& Martinez, M. (2008). Personality disorder symptoms in women as a result of chronic intimate male partner violence. Journal Family Violence, 23(7), 577-588. doi:10.1007/s10896-008-9180-9

Preto, M. \& Moreira, P. A. S. (2012). Auto-regulação da aprendizagem em filhos de vítimas de violência doméstica contra mulheres [Self-regulation of learning in children and adolescents whose mothers were victims of domestic violence]. Psicologia: Reflexão e Crítica, 25(4), 730-737. doi:10.1590/S0102-79722012000400012

Renner, L. M., \& Slack, K. S. (2006). Intimate partner violence and child maltreatment: Understanding intra - and intergenerational connections. Child Abuse \& Neglect, 30(6), 599-617. doi:10.1016/j.chiabu.2005.12.005

Renner, L. M. \& Whitney, S. D. (2010). Examining symmetry in intimate partner violence among young adults using socio-demographic characteristics. Journal of Family Violence, 25(2), 91-106. doi:10.1007/s10896-009-9273-0

Salazar, M., Dahlblom, K., Solórzano, L., \& Herrera, A. (2014). Exposure to intimate partner violence reduces the protective effect that women's high education has on children's corporal punishment: A population-based study. Global Health Action, 7(1), 24774. doi:10.3402/gha.v7.24774 
715 Schütz, E., Archer, T., \& Garcia, D. (2013). Character profiles and adolescents' self-reported

716

717

718

719

720

721

722

723

724

725

726

727

728

729

730

731

732

733

734

735

736

737

738

739

740

741

742

743

744

affect. Personality and Individual Differences, 54(7), 841-844.

doi:10.1016/j.paid.2012.12.020

Sesar, K., Šimic, N., \& Dodaj, A. (2015). Differences in symptoms of depression, anxiety and stress between victims and perpetrators of intimate partner violence. Journal of Sociology and Social Work, 3(2), 63-72. doi:10.15640/jssw.v3n2a7

Sharhabani-Arzy, R., Amir, M., \& Swisa, A. (2005). Self-criticism, dependency and posttraumatic stress disorder among a female group of help-seeking victims of domestic violence in Israel. Personality and Individual Differences, 38(5), 1231-1240. doi:10.1016/j.paid.2004.08.006

Simmons, A. N., Paulus, M. P., Thorp, S. R., Matthews, S. C., Norman, S. B., \& Stein, M. B. (2008). Functional activation and neural networks in women with posttraumatic stress disorder related to intimate partner violence. Biological Psychiatry, 64(8), 681-690. doi:10.1016/j.biopsych.2008.05.027

Simonelli, A., Pasquali, C. E., \& De Palo, F. (2014). Intimate partner violence and drug addicted women: From explicative models to gender-oriented treatments. European Journal of Psychotraumatology, 5(1), 24496. doi:10.3402/ejpt.v5.24496

Stein, M. B., \& Kennedy, C. (2001). Major depressive and post-traumatic stress disorder comorbidity in female victims of intimate partner violence. Journal of Affective Disorders, 66(2-3), 133-138. doi:10.1016/S0165-0327(00)00301-3

Sullivan, K. M., \& Soe, M. M. (2007, Feburary 16). Documentation for Sample Size for an Unmatched Case-Control Study. Retrieved from http://www.openepi.com/PDFDocs/SSCCDoc.pdf

Svrakic, D. M., Draganic, S., Hill, K., Bayon, C., Przybeck, T. R., \& Cloninger, C. R. (2002). Temperament, character, and personality disorders: etiologic, diagnostic, treatment issues. Acta Psychiatrica Scandinavica, 106(3), 189-195. doi:10.1034/j.16000447.2002.02196.x

Svrakic, D. M., Whitehead, C., Przybeck, T. R., \& Cloninger, R. C. (1993). Differential diagnosis of personality disorders by the seven-factor temperament model and character. 
745

746

747 Tsang, J. A. \& Stanford, M. S. (2007). Forgiveness for intimate partner violence: The influence

748

749

750

751

752

753

754

755

756

757

Archives of General Psychiatry, 50(12), 991-999.

doi:10.1001/archpsyc.1993.01820240075009

of victims and offender variables. Personality and Individual Differences, 42(4), 653 664. doi:10.1016/j.paid.2006.08.017

Van Parys, A., Verhamme, A., Temmerman, M., \& Verstraelen, H. (2014). Intimate partner violence and pregnancy: A systematic review of interventions. PLoS ONE, 9(1), e85084. doi:10.1371/journal.pone.0085084

Walker, L. E. A. (2009). The battered woman syndrome (3rd Ed.). New York: Springer Publishing Company.

Zlotnick, C., Johnson, D. M., \& Kohn, R. (2006). Intimate partner violence and long-term psychosocial functioning in a national sample of American women. Journal of Interpersonal Violence, 21(2), 262-275. doi:10.1177/0886260505282564 


\section{Table $\mathbf{1}$ (on next page)}

Demographiccharacteristics of participants. 
Table 1.

Demographic characteristics of participants.

\begin{tabular}{|c|c|c|c|c|c|}
\hline & & $\begin{array}{c}\text { IPV } \\
(n=50)\end{array}$ & $\begin{array}{l}\text { Non-IPV } \\
(n=50)\end{array}$ & $\begin{array}{c}\text { Total } \\
(n=100)\end{array}$ & $\begin{array}{l}\text { IPV vs. Non-IPV } \\
\text { comparison }\end{array}$ \\
\hline & & $M(S E)$ & $M(S E)$ & $M(S E)$ & \\
\hline & Age & $41.2(1.85)$ & $37.4(1.53)$ & $39.3(1.21)$ & $t=1.56, p=.122$ \\
\hline \multirow{5}{*}{ Civil Status } & & $\%$ & $\%$ & $\%$ & \\
\hline & Married & 60 & 56 & 58 & Cramer's $\mathrm{V}=$ \\
\hline & Single & 26 & 38 & 32 & $.169, p=.581$ \\
\hline & Divorced & 6 & 2 & 4 & \\
\hline & Other & 8 & 4 & 6 & \\
\hline \multirow{4}{*}{$\begin{array}{l}\text { Occupation } \\
\text { status }\end{array}$} & Homemaker & 22 & 10 & 16 & Cramer's V = \\
\hline & Student & 2 & 8 & 5 & $.252, p=.095$ \\
\hline & Unemployed & 14 & 6 & 10 & \\
\hline & $\begin{array}{l}\text { Other } \\
\text { occupation }\end{array}$ & 62 & 76 & 69 & \\
\hline \multirow[t]{7}{*}{ Education } & Less than & 84 & 56 & 70 & Cramer's V = \\
\hline & $\begin{array}{l}\text { Secondary } \\
\text { School }\end{array}$ & & & & $.453, p<.001$ \\
\hline & Secondary & 16 & 10 & 13 & \\
\hline & School & & & & \\
\hline & Above & 0 & 34 & 17 & \\
\hline & Secondary & & & & \\
\hline & School & & & & \\
\hline \multirow{3}{*}{$\begin{array}{l}\text { Violence } \\
\text { type }\end{array}$} & Psychological & 20 & - & 10 & - \\
\hline & $\begin{array}{l}\text { Psychological } \\
+ \text { Physical }\end{array}$ & 62 & - & 31 & \\
\hline & $\begin{array}{l}\text { Psychological } \\
+ \text { Physical } \\
+ \text { Sexual }\end{array}$ & 18 & - & 9 & \\
\hline
\end{tabular}




\section{Table 2 (on next page)}

Personality characteristics of women victims ofIPV compared to a control group. 
1

Table 2.

Personality characteristics of women victims of IPV compared to a control group.

\begin{tabular}{|c|c|c|c|c|c|c|c|c|c|}
\hline \multirow[b]{2}{*}{ Personality Dimension } & \multicolumn{2}{|c|}{$\begin{array}{l}\text { IPV Group } \\
(n=50)\end{array}$} & \multicolumn{2}{|c|}{$\begin{array}{l}\text { Non-IPV Group } \\
\qquad(n=50)\end{array}$} & \multicolumn{4}{|c|}{$\begin{array}{c}\text { ANCOVA: } \\
\text { Main effect of Group controlling for } \\
\text { education level }\end{array}$} & \multirow{2}{*}{$\begin{array}{c}\text { Scale } \\
\text { Reliability } \\
\alpha\end{array}$} \\
\hline & $M$ & $S E$ & $M$ & $S E$ & $F$ & $p$ & Partial $\eta^{2}$ & Power & \\
\hline Novelty Seeking & 89.16 & 1.73 & 94.16 & 1.56 & 0.86 & .356 & .01 & .15 & .77 \\
\hline Harm Avoidance* & 109.32 & 2.02 & 98.80 & 2.15 & 5.52 & .021 & .05 & .64 & .88 \\
\hline Reward Dependence** & 97.38 & 1.81 & 105.34 & 1.31 & 7.52 & .007 & .07 & .78 & .78 \\
\hline Persistence & 114.26 & 2.25 & 120.40 & 1.77 & 1.69 & .1196 & .02 & .25 & .86 \\
\hline Self-Directedness $* * *$ & 127.14 & 2.66 & 144.62 & 2.58 & 13.44 & $<.001$ & .12 & .95 & .91 \\
\hline Cooperativeness & 132.82 & 2.04 & 140.66 & 1.85 & 3.53 & .063 & .04 & .46 & .86 \\
\hline Self-Transcendence** & 82.70 & 1.61 & 77.86 & 1.42 & 7.90 & .006 & .08 & .80 & .78 \\
\hline
\end{tabular}

Note. Main effect of education level (covariate) not presented in ANCOVA output. ${ }^{*} \mathrm{p}<.05 .{ }^{* *} \mathrm{p}<.01 .{ }^{* * *} \mathrm{p}<.001$ 


\section{Table 3 (on next page)}

Psychopathological symptoms in women victims ofIPV compared to a control group. 
1

Table 3.

Psychopathological symptoms in women victims of IPV compared to a control group.

\begin{tabular}{|c|c|c|c|c|c|c|c|c|c|}
\hline \multirow[b]{2}{*}{ Symptoms } & \multicolumn{2}{|c|}{$\begin{array}{l}\text { IPV Group } \\
\qquad(n=50)\end{array}$} & \multicolumn{2}{|c|}{$\begin{array}{l}\text { Non-IPV Group } \\
\qquad(n=50)\end{array}$} & \multicolumn{4}{|c|}{$\begin{array}{c}\text { ANCOVA: } \\
\text { Main effect of Group controlling for } \\
\text { education level }\end{array}$} & \multirow{2}{*}{$\begin{array}{c}\text { Scale } \\
\text { Reliability } \\
\alpha\end{array}$} \\
\hline & $M$ & $S E$ & $M$ & $S E$ & $F$ & $p$ & Partial $\eta^{2}$ & Power & \\
\hline Somatization* & 17.06 & 0.78 & 11.74 & 0.62 & 19.53 & $<.001$ & .17 & .99 & .84 \\
\hline Obsession* & 17.64 & 0.73 & 12.16 & 0.51 & 33.38 & $<.001$ & .26 & 1.00 & .84 \\
\hline $\begin{array}{l}\text { Interpersonal } \\
\text { sensitivity* }\end{array}$ & 9.48 & 0.54 & 7.60 & 0.33 & 7.81 & .006 & .08 & .79 & .80 \\
\hline Depression* & 18.10 & 0.84 & 10.42 & 0.55 & 45.43 & $<.001$ & .32 & 1.00 & .91 \\
\hline Anxiety* & 16.46 & 0.80 & 11.10 & 0.51 & 26.06 & $<.001$ & .21 & 1.00 & .86 \\
\hline Hostility* & 11.32 & 0.55 & 8.62 & 0.34 & 16.64 & $<.001$ & .15 & .98 & .77 \\
\hline Phobic Anxiety * & 10.08 & 0.65 & 7.16 & 0.35 & 11.96 & .001 & .11 & .93 & .80 \\
\hline Paranoid ideation & 13.10 & 0.60 & 11.40 & 0.47 & 4.92 & .029 & .05 & .59 & .72 \\
\hline Psychoticism* & 11.58 & 0.65 & 7.56 & 0.35 & 29.40 & $<.001$ & .23 & 1.00 & .80 \\
\hline
\end{tabular}

Note. Main effect of education level (covariate) not presented in ANCOVA output. ${ }^{*} \mathrm{p}<.05$. ${ }^{* *} \mathrm{p}<.01 .{ }^{* * *} \mathrm{p}<.001$ 


\section{Table 4(on next page)}

Correlations between temperament dimensions andpsychopathological symptoms in women victims of IPV $(n=50)$. 
Table 4.

Correlations between temperament dimensions and psychopathological symptoms in women victims of IPV $(n=$ 50).

\begin{tabular}{|c|c|c|c|c|c|c|c|c|c|c|}
\hline \multicolumn{2}{|r|}{ Temperament } & \multicolumn{9}{|c|}{ Psychopathological Symptoms } \\
\hline Subscales & Scales & Somatization & Obsession & $\begin{array}{c}\text { Interpersonal } \\
\text { sensitivity }\end{array}$ & Depression & Anxiety & Hostility & $\begin{array}{l}\text { Phobic } \\
\text { Anxiety }\end{array}$ & $\begin{array}{l}\text { Paranoid } \\
\text { Ideation }\end{array}$ & Psychoticism \\
\hline & Novelty Seeking & -.070 & $-.344 *$ & -.244 & $-.368 *$ & -.173 & $-.307 *$ & -.055 & -.254 & $-.422 *$ \\
\hline NS1 & Exploratory excitability & -.161 & $-.317 *$ & -.220 & $-.356 *$ & -.192 & $-.372 *$ & -.191 & $-.310 *$ & $-.389 *$ \\
\hline NS2 & Impulsiveness & -.029 & -.223 & -.169 & -.252 & -.034 & -.198 & .006 & -.089 & -.240 \\
\hline NS3 & Extravagance & -.024 & -.216 & -.108 & $-.322 *$ & -.035 & -.250 & .033 & -.182 & $-.357 *$ \\
\hline \multirow[t]{2}{*}{ NS4 } & Disorderliness & .053 & -.202 & -.196 & -.074 & -.197 & .007 & .047 & -.072 & -.158 \\
\hline & Harm Avoidance & .199 & $.380 *$ & $.410 *$ & $.302 *$ & $.328 *$ & .269 & .176 & $.463 *$ & $.425^{*}$ \\
\hline HA1 & Anticipatory worry & .201 & $.375^{*}$ & $.431 *$ & $.332 *$ & $.329 *$ & $.373 *$ & .101 & $.535^{*}$ & $.478^{*}$ \\
\hline HA2 & Fear of uncertainty & .096 & .272 & .094 & .151 & .130 & .086 & .202 & .081 & .187 \\
\hline HA3 & Shyness & -.005 & .088 & $.319 *$ & .074 & .171 & .127 & -.017 & $.352 *$ & .166 \\
\hline \multirow[t]{2}{*}{ HA4 } & Fatigability & $.331 *$ & $.453 *$ & $.378 *$ & $.366 *$ & $.371 *$ & .188 & $.312 *$ & $.386^{*}$ & $.449 *$ \\
\hline & Reward Dependence & -.139 & -.227 & -.144 & -.131 & $-.331 *$ & $-.315 *$ & -.150 & $-.389 *$ & -.240 \\
\hline $\mathrm{RD} 1$ & Sentimentality & -.027 & .065 & .085 & .050 & -.047 & -.054 & .073 & -.043 & .035 \\
\hline $\mathrm{RD} 2$ & $\begin{array}{l}\text { Openness to } \\
\text { communication }\end{array}$ & -.107 & -.255 & $-.319 *$ & -.141 & $-.292 *$ & -.247 & -.164 & $-.374 *$ & -.252 \\
\hline RD3 & Attachment & -.228 & $-.393 *$ & $-.440 *$ & $-.339 *$ & $-.418 *$ & $-.400 *$ & -.177 & $-.474 *$ & $-.448 *$ \\
\hline \multirow[t]{2}{*}{$\mathrm{RD} 4$} & Dependence & -.010 & .050 & $-.281 *$ & .136 & -.084 & -.115 & -.099 & -.084 & .097 \\
\hline & Persistence & -.180 & -.269 & -.168 & -.211 & -.232 & -.111 & -.060 & $-.358 *$ & $-.287 *$ \\
\hline PS1 & Resistance to stress & -.195 & $-.352 *$ & -.202 & -.243 & -.210 & -.161 & -.200 & -.243 & -.277 \\
\hline PS2 & Work & -.164 & -.187 & -.192 & -.120 & -.172 & -.099 & -.031 & $-.313 *$ & -.277 \\
\hline PS3 & Ambition & -.059 & -.135 & -.168 & -.127 & -.136 & -.102 & .076 & $-.366^{*}$ & -.232 \\
\hline PS4 & Perfectionism & -.245 & -.266 & -.205 & -.262 & $-.330 *$ & .023 & -.066 & $-.301 *$ & -.187 \\
\hline
\end{tabular}




\section{Table 5 (on next page)}

Correlations between character dimensions andpsychopathological symptoms in women victims of IPV $(n=50)$. 
Table 5.

Correlations between character dimensions and psychopathological symptoms in women victims of IPV $(n=$ 50).

\begin{tabular}{|c|c|c|c|c|c|c|c|c|c|c|}
\hline \multicolumn{2}{|r|}{ Character } & \multicolumn{9}{|c|}{ Psychopathological Symptoms } \\
\hline Subscales & Scales & Somatization & Obsession & $\begin{array}{c}\text { Interpersonal } \\
\text { sensitivity }\end{array}$ & Depression & Anxiety & Hostility & $\begin{array}{l}\text { Phobic } \\
\text { Anxiety }\end{array}$ & $\begin{array}{l}\text { Paranoid } \\
\text { Ideation }\end{array}$ & Psychoticism \\
\hline & Self-Directedness & -.196 & $-.377 *$ & -.037 & $-.380 *$ & -.220 & $-.410 *$ & -.158 & $-.446 *$ & $-.500 *$ \\
\hline SD1 & Responsibility & -.198 & $-.456 *$ & $-.361 *$ & $-.411^{*}$ & -.258 & $-.365 *$ & -.196 & $-.426 *$ &.$- .533 *$ \\
\hline $\mathrm{SD} 2$ & Purposeful & -.162 & $-.390 *$ & $-.295 *$ & $-.417^{*}$ & -.265 & $-.333 *$ & -.170 & $-.368 *$ & $-.499 *$ \\
\hline SD3 & Resourcefulness & -.157 & $-.361 *$ & $-.302 *$ & $-.354 *$ & -.162 & -.208 & -.164 & $-.432 *$ & $-.345^{*}$ \\
\hline SD4 & Self-acceptance & -.061 & -.005 & -.230 & -.091 & -.030 &.$- .383 *$ & .116 & $-.307 *$ & -.185 \\
\hline \multirow[t]{2}{*}{ SD5 } & Congruency & -.160 & -.186 & $-.420 *$ & -.171 & -.089 & -.270 & -.150 & -.220 & $-.295 *$ \\
\hline & Cooperativeness & -.191 & -.061 & -.125 & -.099 & -.135 & $-.301 *$ & -.096 & $-.324 *$ & -.149 \\
\hline $\mathrm{CO} 1$ & Social acceptance & -.136 & -.015 & -.257 & .036 & -.076 & -.263 & -.149 & -.084 & .000 \\
\hline $\mathrm{CO} 2$ & Empathy & -.186 & -.148 & .242 & -.154 & -.201 & -.176 & -.005 & $-.378 *$ & -.223 \\
\hline $\mathrm{CO} 3$ & Helpfulness & -.100 & -.059 & -.266 & -.055 & -.178 & -.188 & -.003 & $-.395 *$ & -.161 \\
\hline $\mathrm{CO} 4$ & Compassion & -.228 & -.145 & -.040 & -.239 & -.189 & $-.429 *$ & -.151 & $-.383 *$ & $-.316 *$ \\
\hline \multirow[t]{2}{*}{$\mathrm{CO} 5$} & Conscience & -.096 & .094 & -.201 & .011 & .066 & -.075 & -.015 & -.110 & .075 \\
\hline & Self-Transcendence & -.126 & -.172 & $-.430 *$ & -.161 & -.266 & -.080 & -.009 & $-.366 *$ & -.253 \\
\hline ST1 & Self-forgetful & -.091 & -.258 & $-.313 *$ & -.196 & -.160 & -.050 & -.073 & -.184 & -.254 \\
\hline ST2 & $\begin{array}{l}\text { Transpersonal } \\
\text { identification }\end{array}$ & -.079 & -.136 & -.134 & -.119 & -.150 & -.174 & .115 & $-.419 *$ & $-.298 *$ \\
\hline ST3 & Spiritual acceptance & -.092 & .053 & -.264 & -.010 & -.248 & .046 & -.041 & -.188 & .024 \\
\hline
\end{tabular}




\section{Table 6(on next page)}

Summary of sevenindependent regression analyses testing predictors of total symptoms $(n=100)$. 
Table 6.

Summary of seven independent regression analyses testing predictors of total symptoms $(n=100)$.

\begin{tabular}{|c|c|c|c|c|c|c|c|}
\hline \multirow[b]{2}{*}{ Model } & \multirow[b]{2}{*}{ Predictors } & \multirow[b]{2}{*}{$b$} & \multirow[b]{2}{*}{$p$} & \multicolumn{4}{|c|}{ Model Summary } \\
\hline & & & & $R^{2}$ & $F$ & $p$ & Power \\
\hline \multirow[t]{6}{*}{ NS } & NS & -0.30 & .245 & .36 & 8.62 & $<.001$ & 1.00 \\
\hline & IPV & 17.07 & .251 & & & & \\
\hline & $\mathrm{NS} \times \mathrm{IPV}^{*}$ & -1.10 & .034 & & & & \\
\hline & Age & -0.07 & .797 & & & & \\
\hline & Education & -1.93 & .668 & & & & \\
\hline & Violence Type & 4.4 .3 & .185 & & & & \\
\hline \multirow[t]{6}{*}{ HA } & $\mathrm{HA}^{*}$ & 0.75 & $<.001$ & .41 & 10.82 & $<.001$ & 1.00 \\
\hline & IPV & 13.86 & .330 & & & & \\
\hline & $\mathrm{HA} \times \mathrm{IPV}$ & 0.46 & .225 & & & & \\
\hline & Age & -0.13 & .960 & & & & \\
\hline & Education & 0.93 & .833 & & & & \\
\hline & Violence Type & 4.02 & .208 & & & & \\
\hline \multirow[t]{6}{*}{$\mathrm{RD}$} & $\mathrm{RD}$ & -0.28 & .318 & .35 & 8.50 & $<.001$ & 1.00 \\
\hline & IPV & 15.53 & .302 & & & & \\
\hline & $\mathrm{RD} \times \mathrm{IPV}$ & -1.03 & .064 & & & & \\
\hline & Age & -0.06 & .819 & & & & \\
\hline & Education & -3.00 & .504 & & & & \\
\hline & Violence Type & 4.47 & .182 & & & & \\
\hline \multirow[t]{6}{*}{ Ps } & Ps & -0.30 & .152 & .35 & 8.21 & $<.001$ & 1.00 \\
\hline & IPV & 15.57 & .300 & & & & \\
\hline & Ps $\times$ IPV & -0.55 & .197 & & & & \\
\hline & Age & -0.13 & .631 & & & & \\
\hline & Education & -2.85 & .528 & & & & \\
\hline & Violence Type & 4.63 & .170 & & & & \\
\hline \multirow[t]{6}{*}{ SD } & $\mathrm{SD}^{*}$ & -0.67 & $<.001$ & .44 & 12.14 & $<.001$ & 1.00 \\
\hline & IPV & 5.96 & .673 & & & & \\
\hline & $\mathrm{SD} \times \mathrm{IPV}$ & -0.25 & .95 & & & & \\
\hline & Age & 0.02 & .943 & & & & \\
\hline & Education & 0.37 & .930 & & & & \\
\hline & Violence Type & 4.93 & .116 & & & & \\
\hline \multirow[t]{6}{*}{$\overline{\mathrm{C}}$} & $\mathrm{C}$ & -0.29 & .190 & .33 & 7.78 & $<.001$ & 1.00 \\
\hline & IPV & 13.69 & .373 & & & & \\
\hline & $\mathrm{C} \times \mathrm{IPV}$ & -0.45 & .303 & & & & \\
\hline & Age & -0.11 & .694 & & & & \\
\hline & Education & -2.95 & .529 & & & & \\
\hline & Violence Type & 4.96 & .148 & & & & \\
\hline \multirow[t]{6}{*}{$\overline{\mathrm{ST}}$} & ST & -0.27 & .336 & .34 & 7.90 & $<.001$ & 1.00 \\
\hline & IPV & 21.45 & .160 & & & & \\
\hline & $\mathrm{ST} \times \mathrm{IPV}$ & -0.83 & .134 & & & & \\
\hline & Age & -0.21 & .439 & & & & \\
\hline & Education & -3.45 & .449 & & & & \\
\hline & Violence Type & 3.93 & .247 & & & & \\
\hline
\end{tabular}


Note. Constant not included in model summaries. NS $=$ Novelty seeking. HA $=$ Harm avoidance. $\mathrm{RD}$ $=$ Reward dependence. $\mathrm{Ps}=$ Persistence. $\mathrm{SD}=$ Self-Directedness. $\mathrm{CO}=$ Cooperativeness. ST $=$ Selftranscendence. IPV $=$ Intimate Partner Violence. ${ }^{*} p<.05$

1 
Figure 1

Personalityprofiles for women victims of IPV (IPV Group) and a control group (nonIPVgroup). Error bars correspond to \pm 1standard error. NS = Novelty Seeking. HA = Harm Avoidance. RD = RewardDependence. Ps $=$ Persistence. SD = Self-Directedness. $\mathrm{C}=\mathrm{CoO}$

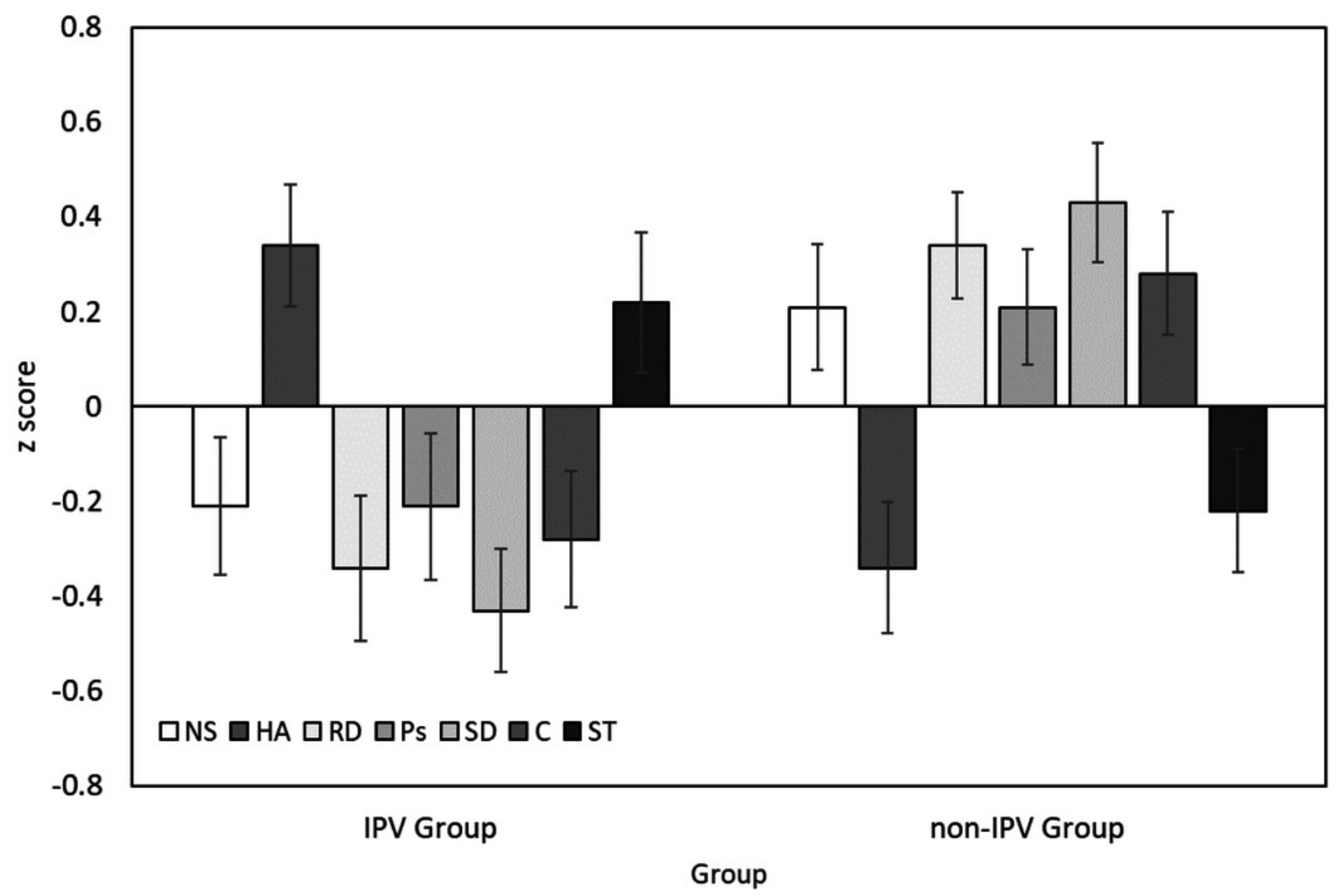


Figure 2

Meanaverage summed scores across BSI symptoms for women victims of IPV (IPV Group)and a control group (Non-IPV Group). Error bars correspond to \pm 1 standard error. Somat. $=$ Somatization. Obs. $=$ Obsession-Compulsion. Int. Sens. = Interpersonal Sens

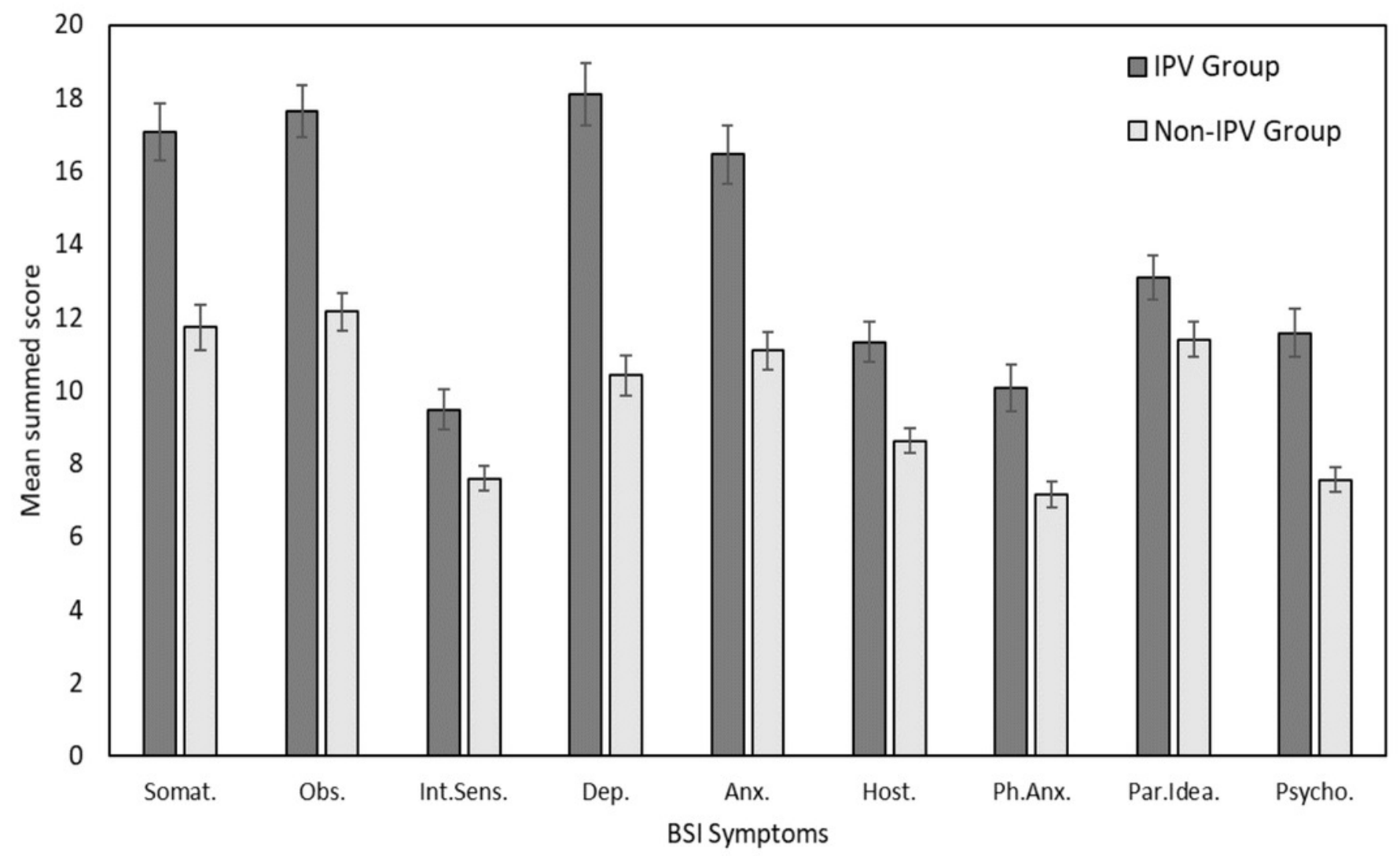


Figure 3

Significant interaction effect of Novelty Seeking (NS) and IPV on total symptoms.

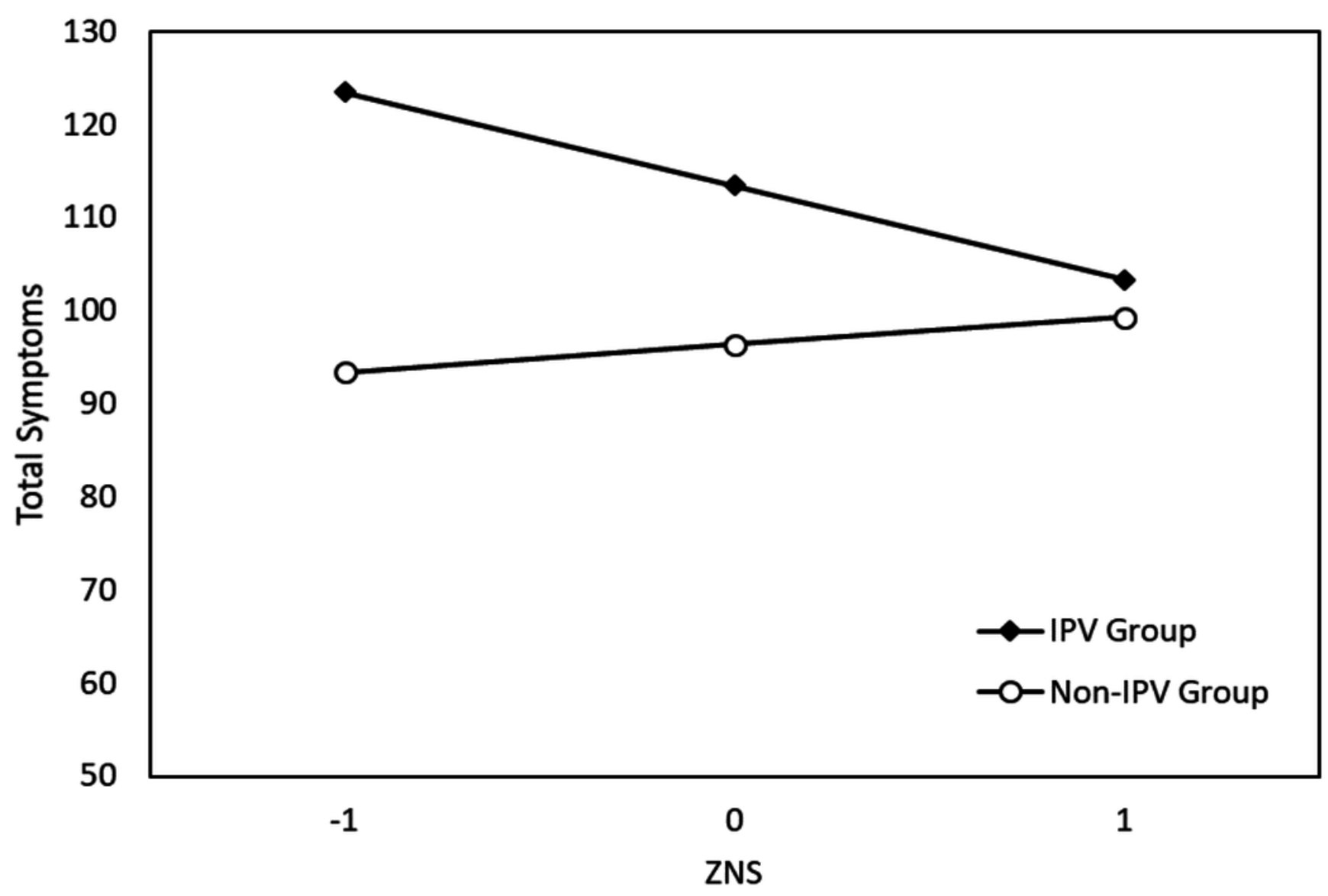

